\title{
Training Effectiveness: An Empirical Examination of \\ Factors Outside The Training Context
}

\author{
J. Bruce Tracey, Ph.D., \\ Cornell University \\ Ithaca, NY 14853
}

Cynthia G. Cardenas, MPS

American Language Institute/CERAN USA

Metter, GA 30439

\begin{abstract}
The influence of factors beyond the immediate training context only recently has been considered in research on training effectiveness. The purpose of this study was to examine the impact of the work environment on pretraining motivation, and the subsequent impact of pretraining motivation on two training effectiveness criteria: knowledge acquisition and training reactions. Using data collected from two foodservice safety training programs, the results from correlation and regression analyses showed that trainee perceptions about managerial support for training, as well as perceptions about the availability of equipment necessary to utilize training, had a direct influence on pretraining motivation. The results also showed that pretraining motivation was directly related to knowledge acquisition and positive reactions to training.
\end{abstract}




\section{Training Effectiveness: An Empirical Examination of Factors Outside The Training Context}

\section{INTRODUCTION}

Hospitality organizations are faced with increasing competitive challenges to improve the quality of services they provide. One method for improving quality is through well-designed and well-executed training programs. A great deal has been written on the importance of training.

One recent example is a series of articles published in Food Management (July, 1994) which described a number of training programs that recently have been implemented in various hospitality and service-sector organizations. One of the featured programs is ARAMARK's Advance Leadership Development Program. The primary objective of this program is to prepare foodservice managers for district-level positions. The content of the program is based on a comprehensive job assessment that identified six major job dimensions deemed necessary for successful job performance (e.g., judgment, adaptability, stress management). The program is implemented in four, week-long training sessions over a nine-month period and focuses on the specific training needs of each trainee. In addition to the weeklong sessions, trainees complete work projects during the interim weeks which provide opportunities to learn more about the relationship between course-specific content and the day-to-day challenges that are encountered in the work place. 
While ARAMARK and others have demonstrated their commitment to the development and implementation of innovative training programs, little emphasis has been placed on evaluating the effectiveness of these programs. A recent study by Conrade, Woods, and Ninemeier (1994) showed that fewer than 10\% of the hospitality organizations they surveyed conducted formal evaluations of their training programs. This is a disappointing statistic, particularly given the increased importance to this vital activity. Similarly, the research on training effectiveness has been somewhat narrow. Most of the research in this area has focused on factors that are directly associated with training content and design, such as training methods and conditions for practice (Noe, 1986; Tannenbaum \& Yukl, 1992). Indeed, there is a great deal of information in the training research literature, as well as the instructional design and education literature, which indicates that factors such as appropriate instructional sequencing, continuous feedback, and strong links between training methods and trainee aptitudes are required for effective training programs (e.g., Gagne \& Dick, 1983; Tannenbaum \& Yukl, 1992). However, it is likely that factors outside the training environment may influence training effectiveness. While a few researchers have recently examined the importance of variables outside the training context (e.g., Mathieu, Tannenbaum, \& Salas, 1992; Tracey, Tannenbaum, \& Kavanagh, 1995), there is still much to be learned. In particular, it is likely that variables in the work environment may have a direct influence on the extent to which desired results are achieved. 
The purpose of this study was to examine factors outside the training context that may influence training effectiveness. This study focused on the influence of perceptions about specific aspect of the work environment on pretraining motivation, and the influence of pretraining motivation on reactions to training and on knowledge acquisition. Research in this area has relevance for both training theory and practice. From a theoretical standpoint, a more comprehensive conceptual framework of training effectiveness can be developed and tested by considering factors outside the formal training context. From an applied standpoint, research-guided enhancements to the work environment may result in increased training effectiveness and utility.

\title{
Pretraining Motivation and The Work Environment
}

\author{
Kirkpatrick (1967) argued that training reactions and learning \\ are two key criteria for evaluating the effectiveness of any training \\ program. Kirkpatrick defined training reactions in terms of \\ perceptions about the value and usefulness of training and defined \\ learning as the knowledge and/or skills acquired during the training \\ experience. It is fairly well-accepted that learning can occur only \\ when individuals have both the ability ("can do") and volition ("will \\ do") to acquire new knowledge (Wexley \& Latham, 1991; Noe, 1986). \\ While a number of studies have examined the "can do" factors (e.g., \\ ability), only a limited number of studies have considered the "will \\ do" factors (cf., Tannenbaum \& Yukl, 1992). One of the "will do" \\ factors that may influence both knowledge acquisition and training
}


reactions is pretraining motivation. Using an expectancy theory framework, Mathieu, Tannenbaum, and Salas (1992) examined the influence of pretraining motivation on knowledge acquisition and training reactions for a proofreading training program for clerical employees. Motivation was operationalized in terms of trainee expectations about the effort-performance and performance-outcome relationships (cf., Vroom, 1964). As hypothesized, Mathieu et al. found that individuals with higher pretraining motivation demonstrated greater learning and more positive reactions to training than individuals with lower pretraining motivation. Tannenbaum, Mathieu, Salas, and Cannon- Bowers (1991) and Baldwin, Magjuka, and Loher (1991) provided additional support for the link between motivation and relevant training outcomes. Thus, it appears that an individual's pretraining motivation is important for successful training.

In addition to pretraining motivation, there is some evidence that the work environment may be important for achieving desired training results. In fact, it appears that the work environment may be an antecedent to pretraining motivation. One dimension of the work environment that may influence pretraining motivation is management's support for training and development efforts. Cohen (1990) found that trainees with supportive supervisors entered training with stronger beliefs that training would be useful. She suggested that supervisors can show their support by discussing the training objectives with trainees prior to training, providing adequate release time to prepare and attend training, and generally encouraging trainees. Baldwin and Magjuka (1991) found that when trainees received relevant information 
before training, recognized that they would be held accountable for learning, and perceived training as mandatory, they reported greater intentions to transfer learning back to their jobs. Thus, the information a trainee receives prior to training may serve as a cue or signal about the value of training, which in turn influences his/ her preparation and motivation for training.

Another dimension of the work environment that may influence pretraining motivation is the resources required to utilize and apply training. As noted above, Mathieu, Tannenbaum, and Salas (1992) found a direct relationship between pretraining motivation and learning and training reactions. Mathieu et al. also found that trainees who reported many "situational constraints" within their work environment (i.e., lack of resources, improper equipment, inadequate time, etc.) entered training with lower levels of motivation than individuals who reported a less- constrained work environment. This study demonstrated that the presence or absence of tools, equipment, supplies, time, and other resources may influence perceptions about the value or importance of training, which subsequently influence motivation to attend and perform during training.

The evidence cited above suggests that if managers support and openly encourage trainees to attend and learn from training, and there are adequate resources necessary to utilize newly acquired knowledge, then trainees may enter training with high levels of motivation and prepared to learn. It also appears that individuals who are motivated for training may acquire relevant knowledge and react positively to the training experience. Mathieu, Tannenbaum, and Salas (1992) 
examined the relationship among constraints in the work environment, pretraining motivation, knowledge acquisition, and training reactions. However, supportive elements of the work environment also appear to be important to pretraining motivation, knowledge acquisition, and positive training reactions. Thus, there is a need to extend previous research and simultaneously examine the influence of facilitators and impediments to pretraining motivation. In addition, it is necessary to confirm the relationship between pretraining motivation and knowledge acquisition and training reactions in hospitality settings.

\section{Summary and Hypotheses}

In order to understand more comprehensively how and why training efforts are successful or not successful, it appears that some consideration must be given to trainees' pretraining motivation and their perceptions about the work environment. To the best of our knowledge, no empirical studies have been conducted to simultaneously examine the influence of these organizational and individual factors on knowledge acquisition and training reactions. Moreover, this is the first hospitality-specific study to examine factors outside the training context that may be important to training effectiveness. Therefore, on the basis of the literature and discussion presented above, the following three hypotheses were developed and tested:

Hypothesis 1: Positive perceptions about managerial support for training will be directly related to pretraining motivation. 
Hypothesis 2: Positive perceptions about the availability of resources necessary to utilize training will be directly related to pretraining motivation.

Hypothesis 3: Pretraining motivation will have a direct effect on reactions to training.

Hypothesis 4: Pretraining motivation will have a direct effect on knowledge acquired during training .

It should be noted that while Kirkpatrick (1967) argued that training reactions should influence knowledge acquisition, Alliger and Janak (1989) found very little support for a direct relationship between these two effectiveness criteria. Thus, separate hypotheses for the reactions and knowledge acquisition dependent variables were developed and tested.

\section{METHOD}

\section{Sample}

This study was conducted in the dining services division of two small, private colleges located in the northeastern United States. The operations in both dining services are very similar. The students of both colleges take classes, live, and eat on both campuses. As such, both dining services have the same menu and schedule of operations. In addition, the management from both dining services operates under similar policies and have joint food production and special events meetings. This high degree of similarity, as well as the lack of significant differences between the two groups on all information 
collected for this study, supports combining the participants from each program into one sample.

Eighty-two individuals were scheduled to participate in a food safety and sanitation training program that was conducted in December, 1994. Complete data from 76 employees were obtained. The participants in this study were line-level employees who represented all major foodservice operations positions (e.g., cooks, prep-workers, utility workers, etc.). About 52\% were female, and the average age was about 41 years. The average number of years of working for their respective college was 7.8 years, and the average number of years experience in the foodservice industry was 14.6 years.

\section{Training}

One of the training programs offered by these colleges is a voluntary program on basic food safety and sanitation. This program was the focal point for the current study. The program consisted of one full day of training in an on-site training facility. Multiple training methods were employed throughout the program, including lecture, discussion, demonstration, and audio-visual techniques.

\section{Procedure}

Approximately three weeks before training, one of the authors administered a survey that asked the participants about their work environment and pretraining motivation. Then, immediately before training (about 30 minutes), a second survey was administered that assessed the participants' pretraining knowledge. This measure, 
developed from the specific objectives outlined in the training materials and interviews with trainers, was used as a baseline to account for knowledge the participants may have had prior to training. Finally, immediately after training, a third survey was administered that assessed the participants' posttraining knowledge and reactions to the training program. All individuals participated in a voluntary manner and were assured that their responses would be confidential.

\section{Measures}

Work Environment

To assess the participants' perceptions about the work environment, seven items used by Mathieu, Tannenbaum, and Salas (1992) and Tracey, Tannenbaum, and Kavanagh (1995) were used. Four items measured the participants' perceptions about management's support for training. An example item was, "Supervisors openly express their support of continuous learning." The remaining three items asked participants their perceptions about the availability of equipment and tools that may be required to utilize newly acquired knowledge. An example item was, 'The unit where I work has the proper equipment to perform my job duties." The response choice format for all items ranged from 1 (strongly disagree) to 5 (strongly agree).

\section{Pretraining Motivation}

Pretraining motivation was assessed using three modified items developed by Tannenbaum, and Salas (1992). These items, based on Vroom's expectancy theory conceptualization of the effort-performance 
relationship (Vroom, 1964), asked participants about their pretraining expectations regarding the upcoming training program. An example item was, "I will try to learn as much as I can in this course." Similar to the work environment measure, the items were modified only to reflect the appropriate frame of reference. The response choice format ranged from 1 (strongly disagree) to 5 (strongly agree).

Knowledge Acquisition

Knowledge acquisition was assessed using pre and posttraining tests. Both measures contained eight identical short-answer items. The items were derived from a content analysis of the training materials by the authors, and then subjected to review by the trainers to ensure the items adequately represented the content of the program. An example item was, "What is the proper holding temperature for potato salad?" The score for each item had a value of one, and the responses were scored by the authors. The order in which the items were administered on the posttraining knowledge assessment was changed to reduce potential testing bias (cf., Campbell \& Stanley, 1967).

\section{Reactions.}

Reactions to training were assessed using five items from the measure developed by Mathieu, Tannenbaum, and Salas (1992). These items asked participants about their posttraining perceptions regarding the usefulness and value of the program, the extent to which the program met their expectations, and so on. An example item was, "This course was valuable to my professional development." The 
response choice format ranged from 1 (strongly disagree) to 5 (strongly agree).

\section{RESULTS}

Means, standard deviations, internal consistency reliability estimates, and correlations among all variables are reported in Table 1. The mean pretraining knowledge score for all trainees was 3.28 with a standard deviation of 2.02. The mean posttraining knowledge score for all trainees was 5.32 with a standard deviation of 1.80. A t-test showed a significant difference between pre and posttraining knowledge $(t=10.55 ; \mathrm{df}=75 ; \mathrm{p}<.01)$, indicating that the trainees knew more about basic safety and sanitation issues at the end of training than before training.

It should be noted that because a control group was not utilized, the differences between pre and posttraining knowledge cannot be conclusively attributed to training. However, the lack of a control group does not pose a problem for testing the primary hypotheses regarding the relationships among perceptions about the work environment, pretraining motivation, knowledge acquisition, and training reactions. The pretest/posttest analysis reported in this study was simply used to demonstrate to the participating organizations that after training, trainees possessed appropriate levels of safety and sanitation knowledge. Sackett and Mullen (1993) argued that a pre-test/post-test research design is appropriate when it is important to assess whether a specific knowledge-, skill-, or ability-level has been achieved, or when it is necessary to document 
individual performance, as was the case for this study. In addition, because adequate learning levels were achieved (according to the organizations' standards), only posttraining knowledge scores were used as a measure of knowledge acquisition.

The results from correlation analyses supported each of the hypotheses. The correlation between perceptions about managerial support and pretraining motivation was $0.26(\mathrm{p}<.05)$. The correlation between perceptions about equipment needed to use training and pretraining motivation was 0.26 ( $\mathrm{p}<.05)$. In addition, pretraining motivation was significantly related to posttraining knowledge (0.19; $\mathrm{p}<.10)$ and reactions $(0.31 ; \mathrm{p}<.05)$. These findings suggest that knowledge acquisition and training reactions are directly related to pretraining motivation, and that the effort that trainees put forth in training is directly related to managerial support and the extent to which trainees have the proper equipment to use their training and perform their job.

A series of multiple and bi-variate regression analyses also supported the hypotheses. Both managerial support and equipment required to utilize training accounted for a significant proportion of variance in pretraining motivation. For managerial support, R2 = .07, $F=5.86(d f=80, p<.05)$, and the beta weight was .26 . For equipment, $\mathrm{R} 2=.07, \mathrm{~F}=5.83(\mathrm{df}=80, \mathrm{p} .05)$, and the beta weight was .26. It should also be noted that when managerial support and equipment were entered simultaneously to predict pretraining motivation, each had significant beta weights in the regression equation and accounted for $11 \%$ of the variance $(.21, .21$, 
respectively, $\mathrm{p}<.05 ; \mathrm{F}=4.92 ; \mathrm{df}=79 ; \mathrm{p}<.01$ ). In addition, pretraining motivation accounted for a significant proportion of variance in both posttraining knowledge and reactions. Pretraining motivation accounted for approximately 5\% of the variance in posttraining knowledge (beta weight $=.19, \mathrm{p}<.10 ; \mathrm{F}=2.82$; df $=74$; $\mathrm{p}<.10)$, and $10 \%$ of the variance in posttraining reactions (beta weight $=.31, \mathrm{p}<.01 ; \mathrm{F}=7.94 ; \mathrm{df}=74 ; \mathrm{p}<.01)$. Therefore, while a great deal of variance was not accounted for, the results from both the correlation and regression analyses fully support all hypotheses.

\section{DISCUSSION}

One of the limitations of prior research on training effectiveness has been the lack of attention to factors other than training content and design. While factors such as instructional sequencing, continuous feedback, and the use of appropriate training methods are vitally important to effective training, it is evident that consideration must be given to factors other than those associated with training content and design in order to gain a more comprehensive understanding of training effectiveness. Specifically, this study demonstrated that managerial support, the availability of equipment and tools necessary for utilizing training, and an individual's pretraining motivation, can influence the extent to which trainees react positively to the training experience and acquire relevant knowledge. Thus, the evidence suggests that the benefits of training may be enhanced by focusing not only on training content, 
design, and implementation, but also the work environment and pretraining motivation.

The workplace can have a very strong influence on employees, and managers must be aware of the cues and signals they send through their actions. In terms of training effectiveness, if managers support training and provide the resources necessary to utilize trained skills and knowledge, it is more likely that training results will be achieved. Support may be demonstrated in a number of ways. For example, managers could discuss the nature and importance of training for an employees development and advancement. In addition, managers could meet with employees to discuss ways in which the knowledge and skills acquired in training may be used to improve both individual and departmental performance. These same discussions could also focus on ways in which equipment and resources may be used to maximize the benefits of training. However, even if employees learn a great deal from a particular program or learning experience, they may not be afforded the opportunity to use their new knowledge or skills because their manager places little value on what was learned and cannot provide the necessary equipment or resources. Thus, if managers understand the value of training, encourage their employees to attend training, and provide the resources necessary to utilize training, then the effectiveness of both formal and informal training programs may be enhanced.

One of the more salient implications of this study is that personnel and process- oriented changes in the workplace may be required before training programs are instituted. For example, jobs 
may need redesigning so that individuals have the necessary time to utilize new knowledge and skills. Or, there may be a need to craft specific policies on training to communicate and reinforce the importance of continuous learning activities. In addition, managers may be required to spend more time with their employees discussing and developing personalized action plans as a means for emphasizing the importance of training.

This study provided ground work for additional research on factors that may influence pretraining motivation, as well as other factors that may impact knowledge acquisition and training reactions. For example, consideration should be given to the influence of an individual's job demands. As suggested above, it is likely that job design may limit or facilitate the extent to which individuals can adequately prepare and subsequently use their training. In addition, the influence of various attitudinal variables such as job commitment, satisfaction, and involvement also should be examined. These individual characteristics may have a significant impact on training success .

At the organizational level, future research also should focus on the influence of appraisal and compensation systems on various training outcomes. For example, if performance appraisal systems are used to account for knowledge and skills that are acquired during training, and valued incentives are provided when trainees successfully demonstrate their newly acquired knowledge and skills, then training results may be realized more quickly and have more lasting effects. In addition, some research has shown a link between 
aggregate measures of organizational climate and culture and training transfer (e.g., Tracey, Tannenbaum, \& Kavanagh, 1995). The influence of these and related variables on pretraining motivation and training performance also should be examined.

\section{Limitations}

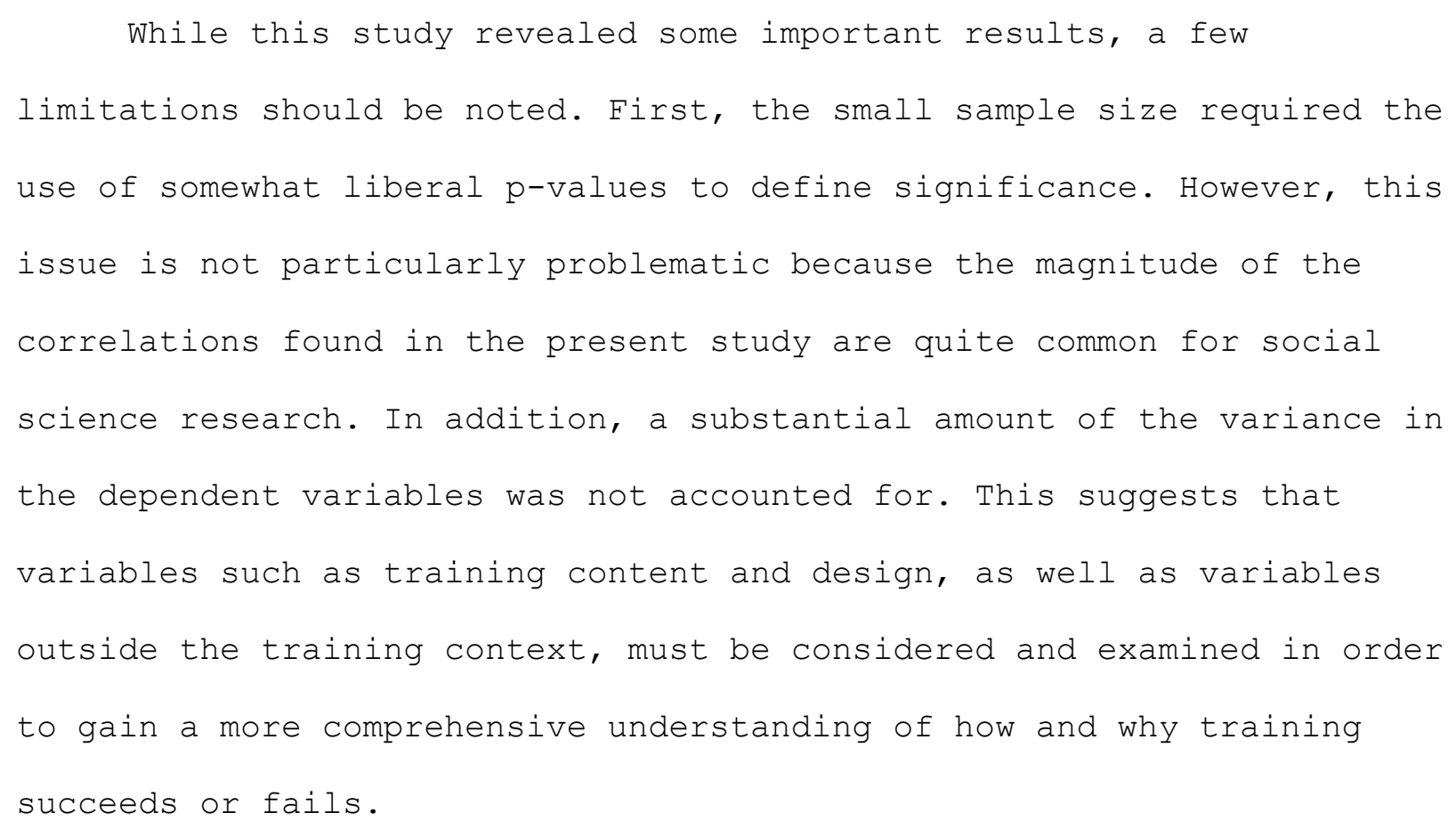

\section{CONCLUSION}

Training has been, and will continue to be, a useful tool for managing many of the current and future challenges in the hospitality industry. However, in order to maximize the return on training investments, we must look beyond the training context in order to understand how and why training works or does not work. This study suggests that a supportive work environment can have a positive influence on employee motivation for training and subsequent training 
success. While the need for additional research is required, this study provides a step toward the development of a more comprehensive understanding of training effectiveness. 
Table 1. Results of Means, Standard Deviations, Internal Consistency Reliability Estimates, and Intecorrelations for Perception of Managerial Support, Resources, Pretraining Motivation, Posttraining Knowledge, and Posttraining Motivation

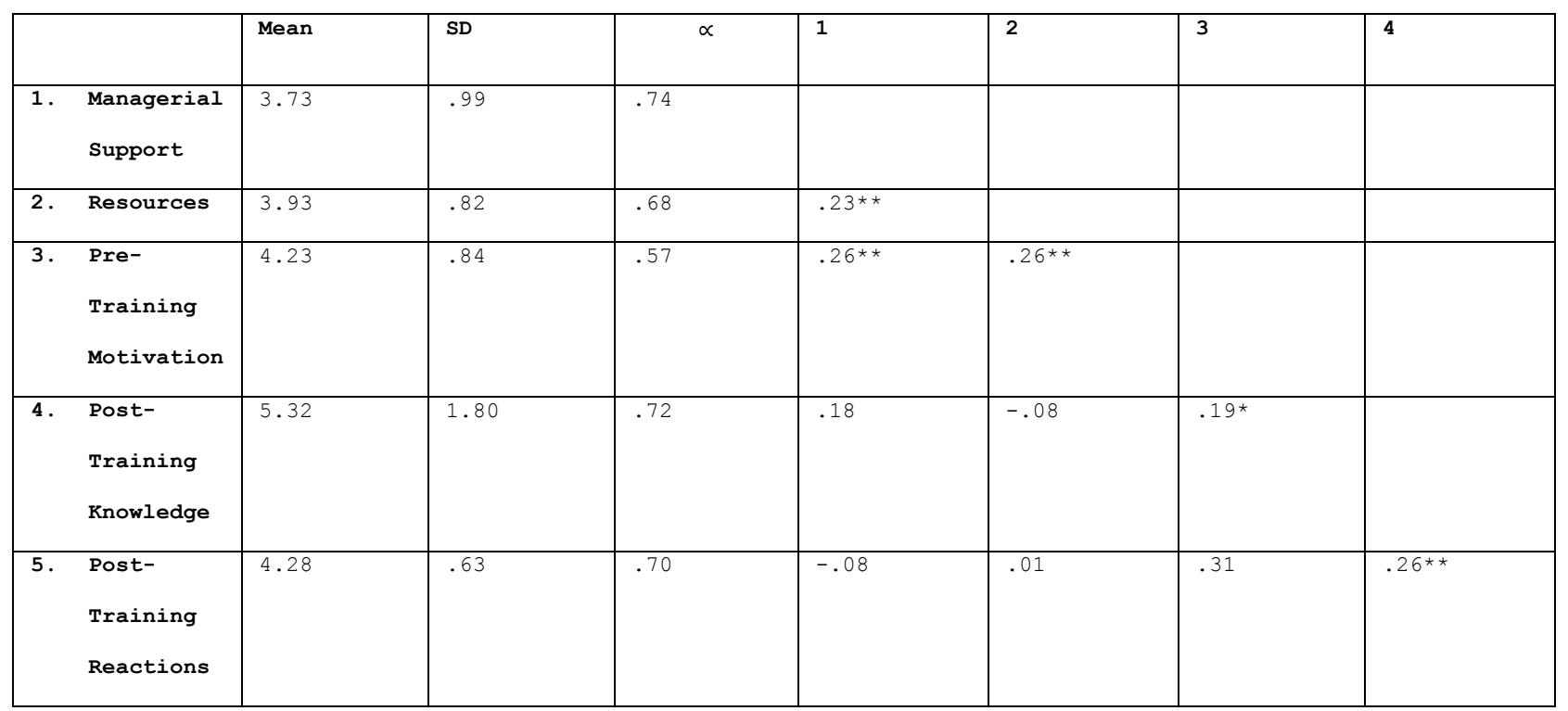

${ }^{*} p<.10$

${ }^{\star} p<.05$ 


\section{REFERENCES}

Alliger, G. M., \& Janak, E. A. (1989). Kirkpatrick's levels of training criteria: Thirty years later. Personnel Psychology, 41, $63-105$

Baldwin, T. T., \& Majguka, R. J. (1991). Organizational training and signals of importance: Linking pretraining perceptions to intentions to transfer. Human Resources Development Quarterly, $2(1), p \cdot 25-36$

Baldwin, T. T., Magjuka, R. J., \& Loher, B. T. (1991). The perils of participation: Effects of choice on trainee motivation and learning. Personnel Psychology, 44, 51-66.

Campbell, D. T. \& Stanley, J. C. (1967). Experimental and quasiexperimental designs for research. Boston, MA: Houghton Mifflin Company.

Cohen, D. J. (1990, October). What motivates trainees. Training and Development Journal, 91-93.

Conrade, G., Woods, R., \& Ninemeier, J. (1994). Training in the U.S. lodging industry: Perception and reality. The Cornell Hotel Restaurant Administration Quarterly, 35, 16-21.

Food Management. (July, 1994) The Labor Files 1994: Part III How to Target Training. 79-86.

Gagne, R. M. \& Dick, W. (1983). Instructional psychology. Annual Review of Psychology, 34, 261-295. 
Kirkpatrick, D. L. (1967). Evaluation of training. In R. L. Craig

(Ed.), Training and Development Handbook: A Guide to Human Resources Development. New York: McGraw-Hill.

Mathieu, J. E., Tannenbaum, S. I., \& Salas, E. (1992). Influences of individual and situational characteristics on measures of training effectiveness. Academy of Management Journal, 35, 828847.

Noe, R. A. (1986). Trainees' attributes and attitudes: Neglected influences on training effectiveness. Academy of Management Review, 11, 736-749.

Sackett, P. R. \& Mullen, E. J. (1993). Beyond formal experimental design: Towards an expanded view of the training evaluation process. Personnel Psychology, 46, 613-627.

Tannenbaum, S. I., Mathieu, J. E., Salas, E. \& Cannon-Bowers, J. A. (1991). Meeting trainees' expectations: The influence of training fulfillment on the development of commitment, self-efficacy, and motivation. Journal of Applied Psychology, 76, 759-769. Tannenbaum, S. I., \& Yukl, G. A. (1992). Training and development in work organizations. The Annual Review of Psychology, 43, 399-441. Tracey, J. B., Tannenbaum S. I., \& Kavanagh, M. J. (1995). Applying trained skills on the job: The importance of the work environment. Journal of Applied Psychology, 80, 239-252. Vroom, V. H. (1964). Work and motivation. New York: Wiley. . Wexley, K. R., \& Latham, G. P. (1991). Developing and training human resources in organizations. New York: Harper Collins. 
J. Bruce Tracey, Ph.D., is an assistant professor at the school of Hotel Administration, Cornell University (Statler Hall, Ithaca, NY 14853). Cynthia G. Cardenas, MPS, is vice president and director of operations of American Language Institute/CERAN USA (Metter, GA 30439). . 